\title{
Effects of exercise training on atrophy gene expression in skeletal muscle of mice with chronic allergic lung inflammation
}

\author{
J.L.Q. Durigan"1, S.M. Peviani ${ }^{1}$, T.L. Russo ${ }^{1}$, A.C.D. Silva², R.P. Vieira ${ }^{2,3}$, M.A. Martins ${ }^{4}$, \\ C.R.F. Carvalho ${ }^{2}$ and T.F. Salvini ${ }^{1}$ \\ ${ }^{1}$ Departamento de Fisioterapia, Universidade Federal de São Carlos, São Carlos, SP, Brasil \\ ${ }^{2}$ Departamento de Fisioterapia, ${ }^{3}$ Departamento de Patologia, ${ }^{4}$ Departamento de Clínica Médica, \\ Faculdade de Medicina, Universidade de São Paulo, São Paulo, SP, Brasil
}

Correspondence to: T.F. Salvini, Departamento de Fisioterapia, UFSCar, Rodovia Washington Luís, km 235, 13565-905 São Carlos, SP, Brasil

Fax: +55-16-3351-2081. E-mail: tania@ufscar.br

\begin{abstract}
We evaluated the effects of chronic allergic airway inflammation and of treadmill training (12 weeks) of low and moderate intensity on muscle fiber cross-sectional area and mRNA levels of atrogin-1 and MuRF1 in the mouse tibialis anterior muscle. Six 4-month-old male BALB/c mice (28.5 $\pm 0.8 \mathrm{~g})$ per group were examined: 1) control, non-sensitized and non-trained (C); 2 ) ovalbumin sensitized (OA, $20 \mu \mathrm{g}$ per mouse); 3) non-sensitized and trained at 50\% maximum speed - low intensity (PT50\%); 4) non-sensitized and trained at $75 \%$ maximum speed - moderate intensity (PT75\%); 5) OA-sensitized and trained at $50 \%$ (OA+PT50\%), 6) OA-sensitized and trained at 75\% (OA+PT75\%). There was no difference in muscle fiber cross-sectional area among groups and no difference in atrogin- 1 and MuRF1 expression between $\mathrm{C}$ and OA groups. All exercised groups showed significantly decreased expression of atrogin- 1 compared to $\mathrm{C}(1.01 \pm 0.2$-fold $)$ : PT50\% $=0.71 \pm 0.12$-fold; OA+PT50\% $=0.74$ \pm 0.03 -fold; PT75\% = 0.71 \pm 0.09 -fold; OA+PT75\% $=0.74 \pm 0.09$-fold. Similarly significant results were obtained regarding MuRF1 gene expression compared to C $(1.01 \pm 0.23$-fold $)$ : PT50 $\%=0.53 \pm 0.20$-fold; OA+PT50 $\%=0.55 \pm 0.11$-fold; PT75\% $=$ $0.35 \pm 0.15$-fold; OA+PT75\% $=0.37 \pm 0.08$-fold. A short period of OA did not induce skeletal muscle atrophy in the mouse tibialis anterior muscle and aerobic training at low and moderate intensity negatively regulates the atrophy pathway in skeletal muscle of healthy mice or mice with allergic lung inflammation.
\end{abstract}

Key words: Exercise training; Muscle atrophy; Asthma; Gene expression; Mice

Research supported by FAPESP (\#05/04413-1 and \#05/54747-3), and Laboratório de Investigação Médica (LIMs 05, 20, and 34), Hospital das Clínicas, Faculdade de Medicina, USP. J.L.Q. Durigan was PhD fellow of CNPq (\#140360/2007-7); T.L. Russo and S.M. Peviani were PhD fellows of FAPESP (\#05/54209-1 and \#05/55773-8, respectively); A.C.D. Silva is the recipient of PhD fellowship from FAPESP (\#06/53965-0), and R.P. Vieira is the recipient of a Post-Doctoral fellowship from FAPESP (\#2007/ 01026-2).

Received August 7, 2008. Accepted February 4, 2009

\section{Introduction}

Asthma is a chronic airway inflammatory disease related to a progressive decrease in lung function and also of the physical capacity to exercise (1). Many clinical and experimental studies have suggested that decreased lung function can be attributed directly to airway inflammation and remodeling $(2,3)$. In addition, decreased physical ca- pacity is normally considered to be secondary to decreased lung function (4), and is strongly related to the psychosocial effects of asthma (5) and to peripheral skeletal muscle disuse (6). These secondary effects have been demonstrated in both asthmatic children and adults (7).

Two recent studies have shown an increase in the mRNA expression of muscle-specific genes related to atrophy in chronic obstructive pulmonary disease (COPD). 
Doucet and colleagues (8) reported an increase in atrogin1 and MuRF1 (232 and 517\%, respectively) mRNA in the quadriceps muscle of patients with COPD. Furthermore, Ottenheijm et al. (9) also showed an increase in atrogin-1 gene expression in the diaphragm muscle of patients with mild to moderate COPD. Atrogin-1 and MuRF1 mRNA levels are reliable molecular markers for muscle atrophy by being increased substantially in peripheral skeletal muscle in various muscle-wasting conditions, such as denervation, immobilization, cancer, sepsis, and aging (10-12). However, the molecular mechanism involved in the skeletal muscle weakness in asthmatic subjects is unknown.

Aerobic physical training has been recommended as an effective adjuvant treatment in the management of asthmatic patients $(13,14)$. Aerobic physical training triggers several beneficial effects in asthmatic patients such as improvement in physical fitness and ventilatory capacity and a decrease in asthma-related symptoms, exerciseinduced bronchospasm, and daily use of inhaled steroids (15-18). Other investigators have demonstrated that asthmatic patients submitted to an aerobic physical training program also present improved respiratory and peripheral muscle strength and function $(19,20)$. However, the mechanisms underlying these effects are unknown.

We recently demonstrated that animals previously submitted to chronic airway allergic inflammation followed by aerobic exercise training presented a decrease in airway inflammation and remodeling in a murine model of asthma (21). Nevertheless, relatively little is known about the effects of aerobic training before the development of the allergic response in peripheral skeletal muscles of asthmatic animals. This aspect should be important because skeletal muscle wasting frequently afflicts asthmatic patients $(5,22,23)$ and it would be important to determine if aerobic training before the induction of asthma could provide some kind of muscle protection.

On the basis of these considerations, we hypothesized that chronic allergic lung inflammation should reduce the cross-sectional area (CSA) of the muscle fibers and increase the expression of atrogin-1 and MuRF1 in the tibialis anterior (TA) muscle. A corollary was that aerobic physical training applied before the induction of chronic allergic lung inflammation could reduce these effects. Since different intensities of aerobic training may induce different adaptations in the asthmatic inflammatory response $(21,24$, 25 ), we analyzed the effect of two aerobic treadmill training intensities in the present study.

Therefore, the purpose of the present study was to evaluate the effects of aerobic treadmill training of low and moderate intensity before and during chronic allergic lung inflammation on the CSA of the muscle fibers and on
mRNA levels of atrogin-1 and MuRF1 in the mouse TA muscle. In view of the similarities among mammalian muscles, the results of this study could provide new information for the understanding and use of treadmill training regarding peripheral muscles in asthma.

\section{Material and Methods}

The study was approved by the review board for human and animal studies of the School of Medicine, University of São Paulo, and was conducted in compliance with the national guidelines of the Guide for Care and Use of Laboratory Animals (26).

\section{Animals and experimental design}

Thirty 4-month-old male BALB/c mice $(28.5 \pm 0.8 \mathrm{~g})$ were randomly divided into 6 groups of 5 animals each: 1 ) non-sensitized and non-trained (control group); 2) ovalbumin-sensitized and non-trained (OA group); 3) non-sensitized and treadmill trained at $50 \%$ maximum speed - low intensity (PT50\%); 4) non-sensitized and treadmill trained at $75 \%$ maximum speed - moderate intensity (PT75\%); 5) OA-sensitized and treadmill trained at $50 \%$ maximum speed (OA+PT50\%), and 6) OA-sensitized and treadmill trained at $75 \%$ maximum speed (OA+PT75\%).

Aerobic exercise treadmill test and aerobic conditioning

Animals were initially adapted to the treadmill for 3 days ( $15 \mathrm{~min}, 0.2 \mathrm{~km} / \mathrm{h}$ ). Next, a maximal exercise capacity test was performed with a 5 -min warm-up $(0.2 \mathrm{~km} / \mathrm{h})$ followed by an increase in treadmill speed (every $2.5 \mathrm{~min}$ ) until animal exhaustion, i.e., after 10 mechanical stimuli (21). Maximal aerobic capacity (100\%) was established as the maximal speed reached by each animal. Mice were exercise trained at low or moderate intensity (50 or $75 \%$ of maximal speed reached in the test, respectively) for $60 \mathrm{~min}$ a day, 5 days a week for 12 weeks ( 8 weeks before sensitization +4 weeks after OA or saline exposure) (21). The improvement in exercise capacity was confirmed by repeating the maximal exercise test after 12 weeks of physical training (72 $\mathrm{h}$ before sacrifice). Non-trained animals were submitted to a protocol that included $5 \mathrm{~min}$ of exercise on the treadmill at $0.5 \mathrm{~km} / \mathrm{h}, 3$ times a week, so that the animals would not present any effect when performing the second and third maximal exercise tests.

\section{Antigen sensitization}

The antigen sensitization period was started during the 9 th week of physical training and lasted for 4 weeks. The mice were sensitized by intraperitoneal (ip) injection of OA (20 $\mathrm{\mu g}$ per mouse) adsorbed with aluminum hydroxide on 
days 0 and 14 or with saline $(0.9 \% \mathrm{NaCl})$, the diluent of $\mathrm{OA}$. During the last week, the mice were challenged with $1 \%$ aerosolized OA or with saline 4 times, every other day, for 30 min per session. Challenging with aerosolized OA (or saline) was performed in an acrylic box (30 x $15 \times 20 \mathrm{~cm})$ coupled to an ultrasonic nebulizer.

\section{Animal anesthesia and euthanasia}

Seventy-two hours after the last training section and antigen sensitization protocols, animals were anesthetized by ip injection of xylazine $(12 \mathrm{mg} / \mathrm{kg})$ and ketamine (95 $\mathrm{mg} / \mathrm{kg}$ ) for muscle dissection and euthanized with an overdose of the anesthetic.

\section{Muscle evaluation}

The TA muscle was chosen because almost all fibers cross the middle belly of the muscle and are distributed from tendon to tendon. In addition, it is a large muscle, and thus allows the evaluation of muscle fiber CSA and gene expression in the same muscle. The mice were weighed and both the right and left TA muscles carefully removed and weighed. The left TA was used for morphological evaluation and was immediately frozen in isopentane, precooled in liquid nitrogen, and stored in a freezer at $-80^{\circ} \mathrm{C}$ (Forma Scientific, USA). Serial cross-sections (10 $\mu \mathrm{m})$ were then obtained from the middle belly of the frozen left TA muscles using a cryostat microtome (Microm HE 505, Germany) and stained with $1 \%$ toluidine blue/1\% borax. The right TA was used for mRNA analysis and was frozen in liquid nitrogen and also stored at $-80^{\circ} \mathrm{C}$, as previously described $(27,28)$.

\section{Muscle fiber cross-sectional area}

One histological cross-section from the middle belly of each left TA muscle was used to measure the muscle fiber CSA in the central region of the histological section. A light microscope (Axiolab, Carl Zeiss, Germany) equipped with a digital camera (Sony DSC S75, Japan) was used. The CSA of 200 randomly chosen fibers per mouse was measured using the Axiovision 3.0.6 SP4 software (Zeiss) $(27,28)$.

\section{RNA isolation and analysis}

RNA was isolated from each frozen right TA muscle using $1 \mathrm{~mL}$ Trizol reagent (Invitrogen, USA) in accordance with manufacturer instructions. The extracted RNA was dissolved in Tris- $\mathrm{HCl}$ and ethylenediaminetetraacetic acid, $\mathrm{pH}$ 7.6, and quantified by spectrophotometry. Purity was assessed by determining the ratio of the absorbance at 260 and $280 \mathrm{~nm}$. All samples had 260/280 $\mathrm{nm}$ ratios above 2.0. RNA integrity was confirmed by inspection of ethidium bromide-stained $18 \mathrm{~S}$ and $28 \mathrm{~S}$ ribosomal RNA under ultra- violet light (Invitrogen).

\section{Reverse transcription}

Total RNA was reverse transcribed to synthesize cDNA in two steps. First, $1 \mu \mathrm{L}$ oligo (dT) primer (Invitrogen) and $9.5 \mu \mathrm{L}$ water were added to $1 \mu \mathrm{g}$ total RNA, heated to $70^{\circ} \mathrm{C}$ for $10 \mathrm{~min}$ and quickly cooled on ice. Second, each sample was incubated in $4 \mu \mathrm{L} 5 \mathrm{X}$ reverse transcription buffer, $1 \mu \mathrm{L}$ of a dNTP (Promega, USA) mixture containing $0.2 \mathrm{mM}$ each of dATP, dCTP, dGTP, and dTTP, $2 \mu \mathrm{L} 0.1 \mathrm{M}$ dithiothreitol and $0.5 \mu \mathrm{L}$ M-MLV RT enzyme (Promega) in a total volume of $20 \mu \mathrm{L}$ at $42^{\circ} \mathrm{C}$ for $60 \mathrm{~min}$. To minimize variation in the reverse transcription reaction, all RNA samples were reverse transcribed simultaneously.

\section{Oligonucleotide primers}

Oligonucleotide primers were designed for atrogin-1 (GenBank, AF441120), MuRF1 (GenBank, AY059627) and GAPDH (AF106860) using the Primer Express Software 2.0 (Applied Biosystems, USA). The sequences used were from rat atrogin-1 (forward: TACTAAGGAGCGCCATGGA TACT; reverse: GTTGAATCTTCTGGAATCCAGGAT), from rat MuRF1 (forward: TGACCAAGGAAAACAGCCAC CAG; reverse: TCACTCCTTCTTCTCGTCCAGGATGG) and from rat GAPDH (forward: CCACCAACTGCTTAG CCC; reverse: GCCAAATTCGTTGTCATACC) genes.

\section{Analysis by the real-time polymerase chain reaction}

mRNA from the experimental and control muscles was amplified with a Rotor Gene 3000 cycler (Cobert's, Sydney, Australia). The amplification mixtures contained $1 \mu \mathrm{L}$ cDNA sample, $25 \mu \mathrm{L}$ of the fluorescent dye SYBR green Master mix (Applied Biosystems) and $180 \mathrm{nM}$ of each primer in a final volume of $50 \mu \mathrm{L}$.

Thermal cycling conditions for atrogin-1, MuRF1 and GAPDH included $10 \mathrm{~min}$ at $95^{\circ} \mathrm{C}$ and then 40 cycles each of $15 \mathrm{~s}$ at $94^{\circ} \mathrm{C}, 30 \mathrm{~s}$ at $56^{\circ} \mathrm{C}$ for atrogin- 1 , at $64^{\circ} \mathrm{C}$ for MuRF1, and at $56^{\circ} \mathrm{C}$ for GAPDH, respectively, and $1 \mathrm{~min}$ at $72^{\circ} \mathrm{C}$, followed by $10 \mathrm{~min}$ at $72^{\circ} \mathrm{C}$. For each gene, all samples were amplified simultaneously in duplicate in one assay run. Data were analyzed using the comparative cycle threshold method. Target gene expression was normalized for the GAPDH gene as reported by others (29).

\section{Statistical analysis}

Levine's test was applied first to evaluate the homogeneity of the results. Two-way ANOVA (factors: exercise and sensitization with $O A$ ) was used to identify possible differences amongst groups. When differences were observed, the Tukey test was applied. For all tests, the level of significance was set at $5 \%(P \leq 0.05)$. 


\section{Results}

Body and tibialis anterior muscle weight and crosssectional area

All groups presented an increase in body weight $(\mathrm{P}<$ 0.05 ) but no statistical difference was found among them (Table 1). Although the weight of the TA muscle was slightly lower in the OA+PT50\% and OA+PT75\% groups, no statistical differences in muscle fiber CSA were detected among the groups studied.

\section{Aerobic exercise capacity}

Figure 1 shows the average improvement in time of maximal exercise between the final and initial tests in all groups. Animals did not present any difference in the first exercise test $(P>0.05)$ and the average exercise time was $39.40 \pm 0.45 \mathrm{~min}$ (data not shown). After 8 weeks, the nontrained groups (control and OA) did not present any improvement in exercise capacity. On the other hand, the trained groups presented statistically significant improvement in maximal exercise capacity in the final test $(P<0.05)$.

\section{Atrogin-1 and MuRF1 gene expression}

Atrogin-1 gene expression was not altered in the OA group compared to control (Figure 2A). However, aerobic training significantly decreased atrogin-1 gene expression in the TA muscles of all trained groups compared to control (1.01 \pm 0.2 -fold): PT50\% = 0.71 \pm 0.12 -fold; OA+PT50\% $=$ $0.74 \pm 0.03$-fold; $\mathrm{PT} 75 \%=0.71 \pm 0.09$-fold; OA+PT75\% = $0.74 \pm 0.09$-fold (Figure 2A)

Similar results were obtained for MuRF1 gene expression, which was unchanged in the OA group compared to control ( $P=0.89$; Figure $2 B$ ). In addition, decreased MuRF1 gene expression was also found in TA muscles after aerobic training compared to control (1.01 \pm 0.23 -fold): PT50\% $=0.53 \pm 0.20$-fold; OA+PT50\% = $0.55 \pm 0.11$-fold; PT75\% $=0.35 \pm 0.15$-fold; OA+PT75\% $=0.37 \pm 0.08$-fold (Figure 2B).

Table 1. Effect of exercise training on body weight, tibialis anterior muscle weight and cross-sectional area.

\begin{tabular}{lcccccc}
\hline & Control & OA & PT50\% & PT75\% & OA+PT50\% & OA+PT75\% \\
\hline Initial body weight $(\mathrm{g})$ & $26.5 \pm 1.8$ & $25.5 \pm 0.8$ & $27.2 \pm 1.4$ & $25.3 \pm 1.1$ & $25.6 \pm 0.7$ & $25.08 \pm 1.3$ \\
Final body weight $(\mathrm{g})$ & $29.3 \pm 1.7$ & $28.8 \pm 1.3$ & $29.7 \pm 1.5$ & $27.7 \pm 0.4$ & $28.3 \pm 1.2$ & $27.1 \pm 0.8$ \\
Gain & $10.8 \%$ & $13.1 \%$ & $9.1 \%$ & $9.3 \%$ & $10.5 \%$ & $7.9 \%$ \\
TA weight $(\mathrm{mg})$ & $57.9 \pm 4.8$ & $54.7 \pm 4.3$ & $54.2 \pm 4.9$ & $56 \pm 3.7$ & $50.4 \pm 4.9^{*}$ & $45.9 \pm 3.7^{*+}$ \\
TA CSA $\left(\mu \mathrm{m}^{2}\right)$ & $1529 \pm 130$ & $1595 \pm 266$ & $1585 \pm 264$ & $1428 \pm 222$ & $1377 \pm 140$ & $1386 \pm 60$ \\
\hline
\end{tabular}

Data are reported as means \pm SD for 5 mice per group. TA $=$ tibialis anterior muscle; CSA $=$ cross-sectional area; Control $=$ nontrained and non-sensitized group; OA = ovalbumin-sensitized group; PT50\% = group submitted to treadmill training at $50 \%$ maximum speed and non-sensitized; PT75\% = group submitted to treadmill training at $75 \%$ maximum speed and non-sensitized; OA+PT50\% = OA-sensitized group submitted to treadmill training at $50 \%$ maximum speed; OA+PT75\% = OA-sensitized group submitted to treadmill training at $75 \%$ maximum speed. ${ }^{*} \mathrm{P}<0.05$ compared to control; ${ }^{+} \mathrm{P}<0.05$ compared to OA, PT50\% and PT75\% (ANOVA and Tukey test).

Figure 1. Effect of training on maximal exercise capacity. Data are reported as means $\pm S D$ of the difference between the first and second tests in minutes for 5 mice in each group. Normal tibialis anterior muscle (control); OA = ovalbumin-sensitized group; PT50\% = group submitted to physical training at $50 \%$ maximum speed and non-sensitized; PT75\% = group submitted to treadmill training at $75 \%$ maximum speed and non-sensitized; $\mathrm{OA}+\mathrm{PT} 50 \%=\mathrm{OA}$-sensitized group submitted to treadmill training at $50 \%$ maximum speed; OA+PT75\% = OA-sensitized group submitted to treadmill training at $75 \%$ maximum speed. ${ }^{*} P<0.05$ compared with non-trained groups (control and OA; ANOVA and Tukey test).

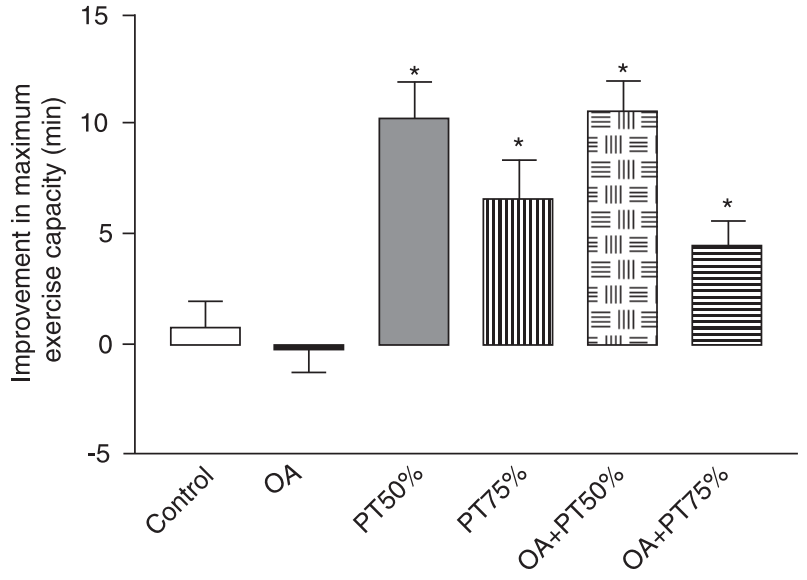




\section{Discussion}

To our knowledge, this is the first study of the effects of prolonged treadmill training of different intensities on the expression of gene markers of muscle atrophy in peripheral skeletal muscle in an atopic asthma mouse model. Lung inflammation did not modify muscle fiber CSA or atrogin-1 and MuRF1 gene expression in the TA muscle. However, treadmill training reduced the expression of these genes in all exercised groups, a fact that could be beneficial in cachexia and disuse conditions.

Recent studies have shown an increase of molecular markers of muscle atrophy in human COPD $(8,9)$. Doucet and colleagues (8) reported an increase in the activation of muscle atrophy by the up-regulation of atrogin- 1 and MuRF1 in the quadriceps muscle of COPD patients. They provided relevant information about a potential molecular mechanism underlying the development of quadriceps muscle atrophy and weakness in these patients, since atrogin-1 and MuRF1 have been found to be markedly up-regulated during cachexia- and disuse-induced atrophy (10-12).

Interestingly, the present results demonstrated that a short period of OA was not effective in inducing muscle atrophy or in modifying the molecular markers for muscle atrophy in mouse TA muscles. These results are interesting when compared with those of Doucet and colleagues (8). Probably, the differences between the present study and the report of Doucet et al. (8) could be related to the different lung diseases and models assessed, since in the present study an asthmatic mouse model was studied, whereas Doucet et al. (8) evaluated COPD disease in humans. The absence of molecular markers for muscle atrophy in the present OA group could be attributed to the short period (4 weeks) of the allergic sensitization protocol, which may not have been long enough to induce skeletal muscle atrophy. Furthermore, although it is difficult to undertake such a study in humans for ethical reasons, future investigations will be necessary for comparative purposes.

Additionally, in the present study the TA muscle was assessed, which is composed of a high percentage of fasttwitch fibers. It should be interesting to examine skeletal muscle with a high percentage of slow-twitch fibers, which are more susceptible to disuse atrophy than fast-twitch fibers (30).

It has been generally accepted that the mouse model of atopic asthma following $\mathrm{OA}$ is similar to asthmatic reaction in humans with regards to airway inflammation (31). Nevertheless, there is little information about whether this model triggers the mechanism of peripheral skeletal muscle weakness and atrophy, as observed in asthmatic subjects.
The results of the present study suggest that only 4 weeks of atopic asthma following OA was not long enough to induce muscle fiber atrophy in the mouse.

In spite of the well-described effects of aerobic training of moderate intensity in eliciting anti-inflammatory effects in asthma $(21,24)$, no information is available regarding the effects of training on peripheral skeletal muscle in this disease. Previous studies have demonstrated that this type of exercise may be used to prevent muscle atrophy under disuse conditions $(32,33)$. The present study showed that treadmill physical training did not alter the CSA of the TA muscle fibers, which is consistent with a study that reported that 12 weeks of treadmill physical training (75\% of $\mathrm{VO}_{2}$ max) had no effect on the CSA of the TA muscle in young rats (33).
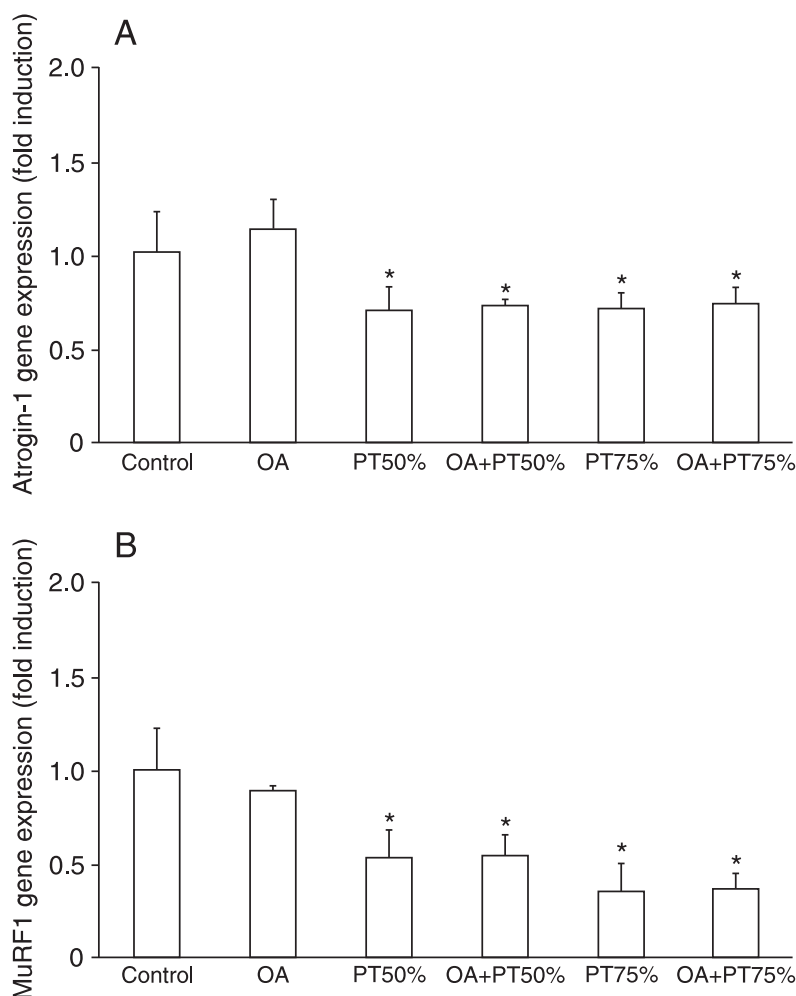

Figure 2. Effect of exercise training on the atrogin-1 (A) and MuRF1 (B) mRNA levels in mouse tibialis anterior muscle. Data are reported as means \pm SD for 5 mice in each group. Normal tibialis anterior muscle (control); $\mathrm{OA}=$ ovalbumin-sensitized group; PT50\% = group submitted to physical training at $50 \%$ maximum speed and non-sensitized; PT75\% = group submitted to treadmill training at $75 \%$ maximum speed and non-sensitized; $\mathrm{OA}+\mathrm{PT} 50 \%=\mathrm{OA}$-sensitized group submitted to treadmill training at $50 \%$ maximum speed; OA+PT75\% = OA-sensitized group submitted to treadmill training at $75 \%$ maximum speed. ${ }^{*} \mathrm{P}<0.05$ for the PT50\%, OA+PT50\%, PT75\%, and OA+PT75\% groups compared to the control group (ANOVA and Tukey test). 
Although the present study did not detect a change in the CSA of the TA muscle fibers after aerobic treadmill training, other studies have demonstrated that aerobic training improves respiratory and peripheral muscle strength and function $(19,20)$, aspects that were not evaluated here.

It is interesting to note that both types of physical training (50 and $75 \%$ ) reduced the accumulation of atrogin1 and MuRF1 mRNA in TA muscle in both asthmatic and non-asthmatic groups compared to non-trained groups. Reduction of atrogin- 1 and MuRF1 mRNA levels by aerobic exercise may provide protection against myoprotein degradation and reduced contractile function inherent to muscle cachexia and disuse. Clinically, these findings should be important in physical rehabilitation, since this protocol was sufficient to change the expression of musclespecific genes related to the atrophy pathway. Nevertheless, studies in humans are also necessary to examine this hypothesis.

Additionally, the evaluation of other muscles, both pe- ripheral (quadriceps and soleus) and respiratory (diaphragm) could be useful for a better understanding of the extent of muscular benefits of aerobic training for asthmatic patients. Aerobic training of low and moderate intensity has been proposed to increase the antioxidant properties and decrease the production of oxidants, resulting in a decrease of muscle damage and in an optimal generation of isometric force $(34,35)$. In spite of the maintenance of muscle fiber CSA observed in the present trained groups, the reduction of reactive oxygen species production inherent to aerobic training $(34,35)$ could justify the decrease of atrogin-1 and MuRF1 expression in trained and non-trained groups, since recent evidence implicates oxidative stress as a key regulator of atrophy cell signaling pathways (36).

\section{Acknowledgments}

The authors are grateful to Tereza F. Piassi, from Federal University of São Carlos, São Carlos, SP, Brazil, for technical assistance.

\section{References}

1. U.S. National Institutes of Health. Global Initiate for Asthma (GINA), from workshop report of global strategy for asthma management and prevention issued 1995 and revised 2006. Washington: Government Printing Office; 2006.

2. Kuhn C III, Homer RJ, Zhu Z, Ward N, Flavell RA, Geba GP, et al. Airway hyperresponsiveness and airway obstruction in transgenic mice. Morphologic correlates in mice overexpressing interleukin (IL)-11 and IL-6 in the lung. Am J Respir Cell Mol Biol 2000; 22: 289-295.

3. Matsumoto H, Niimi A, Takemura M, Ueda T, Minakuchi M, Tabuena $\mathrm{R}$, et al. Relationship of airway wall thickening to an imbalance between matrix metalloproteinase- 9 and its inhibitor in asthma. Thorax 2005; 60: 277-281.

4. Clark CJ, Cochrane LM. Assessment of work performance in asthma for determination of cardiorespiratory fitness and training capacity. Thorax 1988; 43: 745-749.

5. Goldney RD, Ruffin R, Fisher LJ, Wilson DH. Asthma symptoms associated with depression and lower quality of life: a population survey. Med J Aust 2003; 178: 437-441.

6. Mancuso CA, Sayles W, Robbins L, Phillips EG, Ravenell K, Duffy $\mathrm{C}$, et al. Barriers and facilitators to healthy physical activity in asthma patients. J Asthma 2006; 43: 137-143.

7. Lucas SR, Platts-Mills TA. Physical activity and exercise in asthma: relevance to etiology and treatment. J Allergy Clin Immunol 2005; 115: 928-934.

8. Doucet M, Russell AP, Leger B, Debigare R, Joanisse DR, Caron MA, et al. Muscle atrophy and hypertrophy signaling in patients with chronic obstructive pulmonary disease. Am J Respir Crit Care Med 2007; 176: 261-269.

9. Ottenheijm CA, Heunks LM, Li YP, Jin B, Minnaard R, van
Hees HW, et al. Activation of the ubiquitin-proteasome pathway in the diaphragm in chronic obstructive pulmonary disease. Am J Respir Crit Care Med 2006; 174: 997-1002.

10. Lecker SH, Jagoe RT, Gilbert A, Gomes M, Baracos V, Bailey $\mathrm{J}$, et al. Multiple types of skeletal muscle atrophy involve a common program of changes in gene expression. FASEB J 2004; 18: 39-51.

11. Lecker SH, Solomon V, Mitch WE, Goldberg AL. Muscle protein breakdown and the critical role of the ubiquitinproteasome pathway in normal and disease states. $J$ Nutr 1999; 129: 227S-237S.

12. McKinnell IW, Rudnicki MA. Molecular mechanisms of muscle atrophy. Cell 2004; 119: 907-910.

13. American Association of Cardiovascular and Pulmonary Rehabilitation. Guidelines of pulmonary rehabilitation programs. 2nd edn. Champaign: Human Kinetics; 1998.

14. British Thoracic Society Standards of Care Subcommittee on Pulmonary Rehabilitation. Pulmonary rehabilitation. Tho$\operatorname{rax} 2001$; 56: 827-834.

15. Carroll N, Sly P. Exercise training as an adjunct to asthma management? Thorax 1999; 54: 190-191.

16. Fanelli A, Cabral AL, Neder JA, Martins MA, Carvalho CR. Exercise training on disease control and quality of life in asthmatic children. Med Sci Sports Exerc 2007; 39: 14741480.

17. Neder JA, Nery LE, Silva AC, Cabral AL, Fernandes AL. Short-term effects of aerobic training in the clinical management of moderate to severe asthma in children. Thorax 1999; 54: 202-206.

18. Ram FS, Robinson SM, Black PN, Picot J. Physical training 
for asthma. Cochrane Database Syst Rev 2005; CD001116.

19. Counil FP, Varray A, Matecki S, Beurey A, Marchal P, Voisin $\mathrm{M}$, et al. Training of aerobic and anaerobic fitness in children with asthma. J Pediatr 2003; 142: 179-184.

20. Counil FP, Voisin M. Physical fitness in children with asthma. Arch Pediatr 2006; 13: 1136-1141.

21. Vieira RP, Claudino RC, Duarte AC, Santos AB, Perini A, Faria Neto HC, et al. Aerobic exercise decreases chronic allergic lung inflammation and airway remodeling in mice. Am J Respir Crit Care Med 2007; 176: 871-877.

22. Dimitrijevic MM, Dimitrijevic MR. Clinical elements for the neuromuscular stimulation and functional electrical stimulation protocols in the practice of neurorehabilitation. Artif Organs 2002; 26: 256-259.

23. McComas AJ. Human neuromuscular adaptations that accompany changes in activity. Med Sci Sports Exerc 1994; 26: 1498-1509.

24. Pastva A, Estell K, Schoeb TR, Atkinson TP, Schwiebert LM. Aerobic exercise attenuates airway inflammatory responses in a mouse model of atopic asthma. $\mathrm{J}$ Immunol 2004; 172: 4520-4526.

25. Ram FS, Robinson SM, Black PN. Effects of physical training in asthma: a systematic review. Br J Sports Med 2000; 34: 162-167.

26. National Research Council. Guide for the care and use of laboratory animals. Washington: National Academy Press; 1996.

27. Peviani SM, Gomes AR, Moreira RF, Moriscot AS, Salvini TF. Short bouts of stretching increase myo-D, myostatin and atrogin-1 in rat soleus muscle. Muscle Nerve 2007; 35: 363-370.
28. Russo TL, Peviani SM, Freria CM, Gigo-Benato D, Geuna $\mathrm{S}$, Salvini TF. Electrical stimulation based on chronaxie reduces atrogin- 1 and myoD gene expressions in denervated rat muscle. Muscle Nerve 2007; 35: 87-97.

29. Luden N, Jemiolo B, Whitsett D, Trappe S. Effects of 13 weeks of aerobic training on basal gene expression. FASEB J 2007; 21: 921-929.

30. Lieber RL. Skeletal muscle structure, function, and plasticity, the physiological basis of rehabilitation. Philadelphia: Lippincott; 2002.

31. Tang LF, Du LZ, Zou CC, Gu WZ. Levels of matrix metalloproteinase- 9 and its inhibitor in guinea pig asthma model following ovalbumin challenge. Fetal Pediatr Pathol 2005; 24: 81-87.

32. Diaz-Herrera P, Torres A, Morcuende JA, Garcia-Castellano JM, Calbet JA, Sarrat R. Effect of endurance running on cardiac and skeletal muscle in rats. Histol Histopathol 2001; 16: 29-35.

33. Song W, Kwak HB, Lawler JM. Exercise training attenuates age-induced changes in apoptotic signaling in rat skeletal muscle. Antioxid Redox Signal 2006; 8: 517-528.

34. Faucher M, Steinberg JG, Barbier D, Hug F, Jammes Y. Influence of chronic hypoxemia on peripheral muscle function and oxidative stress in humans. Clin Physiol Funct Imaging 2004; 24: 75-84.

35. Reid MB. Invited Review: redox modulation of skeletal muscle contraction: what we know and what we don't. $J$ Appl Physiol 2001; 90: 724-731.

36. Powers SK, Kavazis AN, McClung JM. Oxidative stress and disuse muscle atrophy. J Appl Physiol 2007; 102: 23892397. 